\title{
Effect of mycorrhiza on yield and quality of lettuce grown on medium with different levels of phosphorus and selenium
}

\author{
Iwona Kowalska and Anna Konieczny \\ Unit of Plant Nutrition, Institute of Plant Biology and Biotechnology, Faculty of Biotechnology and Horticulture, University of \\ Agriculture in Kraków, 29 Listopada 54, 31-425 Krakow, Poland \\ e-mail: rokowals@cyf-kr.edu.pl
}

\begin{abstract}
Lettuce plants were grown in the foil tunnel in pots filled with peat substrate. The experimental factors were: concentration of phosphorus in the substrate $\left(70\right.$ or $\left.140 \mathrm{mg} \mathrm{dm}^{-3}\right)$, inoculation of substrate with arbuscular mycorrhizal fungi (+AMF or -AMF) and concentration of selenium in the substrate $\left(0,6\right.$ or $\left.12 \mathrm{mg} \mathrm{dm}^{-3}\right)$. Mycorrhizal frequency in roots was affected by concentration of $\mathrm{P}$, inoculation with AMF and interaction between these factors. Higher mycorrhizal frequency was found in plants inoculated with AMF and grown under conditions of lower $P$ concentration. AMF did not affect an accumulation of Se in leaves. However, higher concentration of $P$ and $S e$ in the substrate affected Se concentration in leaves. The average yield of lettuce decreased with increasing level of Se in the substrate. The presence of $\mathrm{Se}$ in the substrate led to decrease of $\mathrm{K}, \mathrm{Mg}, \mathrm{Fe}, \mathrm{Cu}$ and $\mathrm{Mn}$ content of plants. AMF did not have an effect on the content of sugars in leaves.
\end{abstract}

Key words: mineral composition, biofortification, symbiosis

\section{Introduction}

Arbuscular mycorrhizal fungi (AMF) live in symbiosis with more than $80 \%$ of plant species. Fungal hyphae increase the absorption surface of roots, which may contribute to the improvement of plant nutritional status. The development of mycorrhizal structures is affected by environmental conditions, i.e., content of nutrients in the plant root zone, especially $\mathrm{P}$, as well as the $\mathrm{pH}$, temperature, soil moisture or light intensity (Gryndler et al. 2006, Cordeiro Silva et al. 2014). Phosphorus concentration in the plant root zone is the main factor affecting development of AMF structure (Schmidt et al. 2010, Cordeiro Silva et al. 2014). Schmidt et al. (2010) studied the cultivation of marigolds in perlite inoculated by three species of AMF and demonstrated significant inhibition of mycorrhiza development in roots of plants receiving Hoagland's solution with optimal and doubled concentration of $\mathrm{P}$, compared to plants receiving Hoagland's solution in which the concentration of this macronutrient was decreased by 50 or $75 \%$. Amijee et al. (1989) observed a significant reduction in colonized roots of leeks under conditions of increased $\mathrm{P}$ concentration in soil.

Se is a necessary component in the metabolism of mammals and its deficiency contributes to the many serious diseases. For plants, Se is not considered as essential (Lyons et al. 2009, Pilon-Smits et al. 2009). However, plants are able to uptake, metabolise and accumulate this element. There are an increasing number of studies proving that low concentration of Se has a beneficial effect on plants due to activation of mechanisms mitigating antioxidant stress or even playing an anti-oxidative role (Hawrylak and Szymańska 2007). Most of the European soils are low in Se, therefore, in some countries (e.g. Finland) fertilisation of soil with Se in the form of sodium selenite is very common. Presence of AMF, due to the increased absorptive surface of the root system, could affect Se uptake. Moreover, it can be assumed that, if AMF increases the solubility of nutrients which are often present in forms unavailable to plants (i.e. P), a similar mechanism could work for unavailable forms of Se. Production of plants with increased content of Se, which could be achieved as a result of symbiosis with AMF, seems to be safe method for enrichment of the human diet with this nutrient.

The aim of the study was to determine the effect of AMF on Se uptake by lettuce. The experiment was carried out under conditions of different concentrations of $\mathrm{P}$ and $\mathrm{Se}$ in the plant root zone. 


\section{Material and methods}

The experiment was carried out in a foil tunnel over in two spring seasons. Lettuce plants (cv. Valeska) were grown in pots with a capacity of $2 \mathrm{dm}^{3}$ and filled with peat substrate. The experiment was conducted in three-factor system and the experimental factors were as follows: inoculation of plant roots with AMF or lack of it (+AMF/-AMF), content of $P$ in the substrate $\left(140 \mathrm{mg} \mathrm{dm}^{-3}\right.$, the optimal level, or $\left.70 \mathrm{mg} \mathrm{dm}^{-3}\right)$ and content of Se $\left(0,6\right.$ or $\left.12 \mathrm{mg} \mathrm{dm}^{3}\right)$. $\mathrm{P}$ was added to the substrate in the form of triple superphosphate $\mathrm{Ca}\left(\mathrm{H}_{2} \mathrm{PO}_{4}\right)_{2}$ and $\mathrm{Se}$ in the form $\mathrm{Na}_{2} \mathrm{SeO}_{3}$. Part of the peat substrate within each Se concentration was inoculated with inoculum containing Rhizophagus intraradices (SYMBIOM, 720 propagules per $1 \mathrm{~g}$ ) at an inoculum concentration of $8.5 \mathrm{~g}$ per 2 liters of the substrate. All fertilizers and then the inoculum were separately mixed with the substrate before planting.

The experiment was conducted using a randomized block design. Each experimental factor was performed in triplicate and six plants were used for each replicate. To sum up, 216 plants were used in the experiment ( 2 levels of $\mathrm{P} \times 3$ levels of Se $\times 2$ inoculation types $\times 3$ replicates $\times 6$ plants for each replicate).

Untreated lettuce seeds were sown in multi-pots filled with peat substrate, which had been limed and supplemented with nutrients to the level recommended for the production of lettuce seedlings. When seedlings had 3-4 fully developed leaves, they were transferred to pots filled with peat substrate. Peat substrate was prepared using moss peat $\left(\right.$ Kronen $\left.^{\circledR}\right)$, limed according to a neutralization curve to $\mathrm{pH}$ 6.0. The content of nutrients, with the exception of $\mathrm{P}$ and Se, for all plants was supplemented as follows (in $\mathrm{mg} \mathrm{dm}^{-3}$ ): $\mathrm{N}-180, \mathrm{~K}-220, \mathrm{Mg}-160, \mathrm{Fe}-20, \mathrm{Mn}-20$, $\mathrm{Cu}-5, \mathrm{~B}-1$ and $\mathrm{Mo}-1$. The plants were irrigated with tap water using a drip irrigation system. The frequency of irrigation was adjusted to the plant growth stage. There was no top-dress fertilisation during the growing season. Depending on the sunlight, temperature in the tunnel was kept between 16 and $21^{\circ} \mathrm{C}$ during the day and at $12{ }^{\circ} \mathrm{C}$ at night. Plants were harvested 46 days after planting the seedling in the pots, during the phase of formed heads.

\section{Observation and measurements \\ Mycorrhizal colonisation}

The root system of plants was collected at the time of harvest in order to determine the colonisation of plants by AMF. Three root systems were collected from each replicate of each experimental combination.

Samples weighing $10 \mathrm{~g}$ were collected from the root systems and were used to prepare microscope slides according to a modified method of Phillips and Hayman (1970). The collected roots were cold-macerated in $10 \% \mathrm{KOH}$ $(12 \mathrm{~h})$, rinsed with water, acidified with $5 \%$ lactic acid $(12 \mathrm{~h})$ and stained with $0.03 \%$ aniline blue dissolved in a mixture of lactic acid, glycerol and distilled water $(1: 1: 1 \mathrm{v} / \mathrm{v} / \mathrm{v})$. The duration of maceration and acidification was limited to $12 \mathrm{~h}$ due to the delicate structure of lettuce roots. Microscope slides were prepared from stained roots, cut into $1 \mathrm{~cm}$ length pieces and encapsulated in a mixture of glycerol and lactic acid $(5: 1 \mathrm{v} / \mathrm{v})$. The prepared slides were examined using an Axio Imager N2 (Carl Zeiss) microscope with Nomarsky optics. Each replicate was represented by 90 pieces of root, each having a length of $1 \mathrm{~cm}$. The colonization of lettuce roots by AMF was assessed according to the method of Trouvelot et al. (1986) by determining the following parameters: mycorrhizal frequency $(F)$, relative mycorrhizal intensity $(M)$ and relative abundance of arbuscules $(A)$. These mycorrhizal parameters were calculated using Mycocalc software (http://www2.dijon.inra.fr/mychintec/Mycocalc-prg/download.html).

\section{Yield}

Lettuce plants were harvested from each replicate separately, plants were weighed and the average weight of single head was calculated. Yield of lettuce was expressed as the weight of a single head.

\section{Quality of lettuce}

Five representative plants from each replicate were selected for chemical analysis of the plant material. One-half of each lettuce head was chopped in a blender. Dry matter content was assessed at $105^{\circ} \mathrm{C}$. In order to determine the content of sugars, fresh leaves were extracted with boiling $96 \%$ ethanol using a reflux condenser. The content of glucose, fructose and sucrose were assessed by capillary electrophoresis system (Beckman Coulter PA 800 plus Pharmaceutical Analysis System) using a kit from Analyst Scientific Instruments for Laboratories (Belgium) $\left(\mathrm{NaH}_{2} \mathrm{PO}_{4}(36 \mathrm{mmol}), \mathrm{NaOH}(130 \mathrm{mmol}), \beta\right.$-cyclodextrin $\left.\mathrm{pH}=12.7\right)$ were determined. Capillaries of $25 \mu \mathrm{m}$ i.d. and 
$365 \mu \mathrm{m}$ o.d. and those of a total length of $60 \mathrm{~cm}(50 \mathrm{~cm}$ to detector) were used. A power supply of $30 \mathrm{kV}$ normal polarity was used. The detector was set at $205 \mathrm{~nm}$.

The remaining half of each lettuce was dried at $65^{\circ} \mathrm{C}(24 \mathrm{~h})$ in a laboratory dryer with forced air circulation. Dried samples were ground in a variable speed rotor mill (Pulverisette 14; FRITSH) using a 0.05-mm sieve. The content of $\mathrm{P}, \mathrm{K}, \mathrm{Ca}, \mathrm{Mg}, \mathrm{Cu}, \mathrm{Fe}, \mathrm{B}, \mathrm{Mn}, \mathrm{Mo}$ and $\mathrm{Zn}$ was determined after mineralization in $65 \%$ extra pure $\mathrm{HNO}_{3}$ in a $\mathrm{CEM}$ MARS-5 Xpress microwave system (Pasławski and Migaszewski 2006), using a high-dispersion spectrometer ICPOES (Leeman Labs). The $\mathrm{N}$ content in leaves was determined by the Kjeldahl method using a VELP Scientifica UDK 193 distillation unit (Persson and Wennerholm 1999). The Se content was determined after tetramethylammonium hydroxide (TMAH) extraction. Air-dried leaf or root samples $(0.5 \mathrm{~g}), 10 \mathrm{~cm}^{3}$ double-distilled water and $1 \mathrm{~cm}^{3}$ of $25 \%$ TMAH (Sigma-Aldrich) were added to $30 \mathrm{~cm}^{3}$ Falcon tubes. After mixing, samples were incubated for $3 \mathrm{~h}$ at $90^{\circ} \mathrm{C}$. After incubation, samples were cooled to a temperature of approximately $20^{\circ} \mathrm{C}$ and the volume made up to $30 \mathrm{~cm}^{3}$ with double-distilled water. After mixing, samples were centrifuged for $15 \mathrm{~min}$ at $4500 \mathrm{rpm}$. The measurements of I and Se content using an ICP-OES spectrometer (Leeman Labs) were conducted with the supernatant without decanting (PN-EN 15111 2008).

\section{Statistical analysis}

Since there were no differences between the two years of the study, the average values obtained in the two years were subjected to three-way analysis of variance using the ANOVA module (Statistica 10.0 PL). Tukey's test was used to determine significant differences between the mean values. Differences were considered as significant at $p<0.05$.

\section{Results and discussion}

The effectiveness of lettuce inoculation by commercial inoculum containing AMF was demonstrated in the experiment (Table 1). Mycorrhizal frequency (F) and relative mycorrhizal intensity (M) in roots of plants inoculated with AMF (+AMF) was $21.73 \%$ and $0.61 \%$, respectively, and was significantly higher than in non-inoculated plants. Both parameters ( $F$ and $M$ ) were affected by the $P$ content of the substrate. Higher $F$ and $M$ was estimated in roots of plants grown under conditions of lower $P$ concentration $\left(70 \mathrm{mg} \mathrm{dm}^{-3}\right)$ in the substrate $(16.17 \%$ and $0.48 \%$, respectively) than in roots of plants grown with a standard $P$ concentration $\left(140 \mathrm{mg} \mathrm{dm}^{-3}\right)$ in the substrate $(5.56 \%$ and $0.13 \%$, respectively). Moreover, the interaction between $\mathrm{P}$ level in the substrate and inoculation with AMF on mycorrhizal parameters ( $F$ and $M$ ) was demonstrated in the experiment. The $P$ level did not affect $F$ in roots of non-inoculated plants.

Table 1. Mycorrhizal frequency (F), relative mycorrhizal intensity (M) and relative abundance of arbuscules $(A)$ in lettuce roots grown on medium with different levels of phosphorus and selenium $\left(\mathrm{mg} \mathrm{dm}^{-3}\right)$

\begin{tabular}{|c|c|c|c|c|}
\hline Treatments & & $\mathrm{F}$ & M & A \\
\hline & & & $\%$ & \\
\hline \multirow[t]{2}{*}{ Phosphorus } & 70 & 16.17 & 0.48 & 0.064 \\
\hline & 140 & 5.56 & 0.13 & 0.198 \\
\hline \multirow[t]{2}{*}{ Mycorrhiza } & $-\mathrm{AMF}$ & 0.00 & 0.00 & 0.000 \\
\hline & $+\mathrm{AMF}$ & 21.73 & 0.61 & 0.263 \\
\hline \multirow[t]{3}{*}{ Selenium } & 0 & 10.93 & 0.32 & 0.097 \\
\hline & 6 & 10.19 & 0.30 & 0.000 \\
\hline & 12 & 11.48 & 0.29 & 0.298 \\
\hline \multirow[t]{7}{*}{$p<0.05$} & Phosphorus (A) & $*$ & $*$ & n.s. \\
\hline & $\mathrm{AMF}(\mathrm{B})$ & $*$ & $*$ & n.s \\
\hline & Selenium (C) & n.s. & n.s. & n.s. \\
\hline & $A \times B$ & $*$ & $*$ & n.s \\
\hline & $A \times C$ & n.s. & n.s. & n.s. \\
\hline & $B \times C$ & n.s & n.s & n.s \\
\hline & $A \times B \times C$ & n.s. & n.s. & n.s. \\
\hline
\end{tabular}


However, in inoculated plants higher $F$ was estimated in roots of plants grown at a lower level of $P$ in the substrate (Fig. 1). Relative mycorrhizal intensity (M) was at the same level in non-inoculated plants, regardless of the $P$ level in the substrate, and in inoculated plants grown at $140 \mathrm{mg} \mathrm{dm}^{-3} \mathrm{P}$. Higher relative mycorrhizal intensity was determined in roots of inoculated plants grown at $70 \mathrm{mg} \mathrm{P} \mathrm{dm}^{-3}$ (Fig. 2).
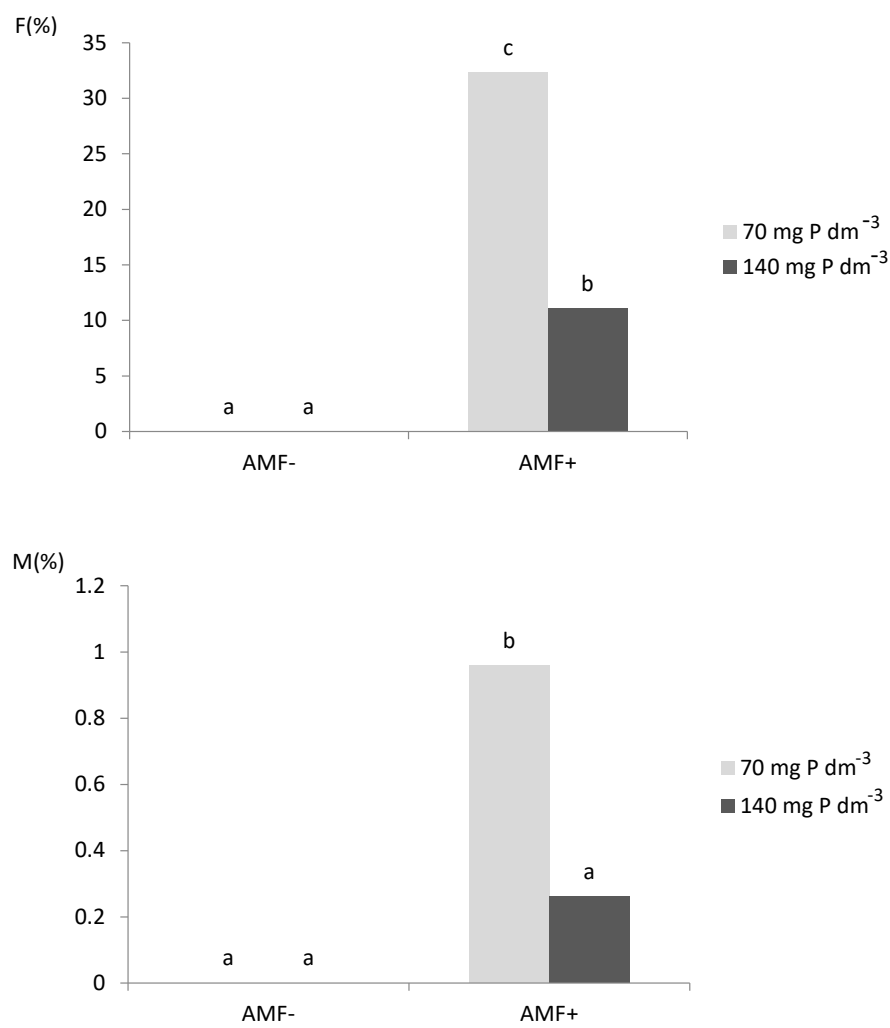

Fig. 1. Interaction between the level of phosphorus and inoculation or non-inoculation with arbuscular mycorrhizal fungi (AMF) on the mycorrhizal frequency $(F)$. Means followed by different letters differ at $p<0.05$

Fig. 2. Interaction between the level of phosphorus and inoculation or non-inoculation with arbuscular mycorrhizal fungi (AMF) on the relative mycorrhizal intensity (M). Means followed by different letters differ at $p<0.05$

A negative effect of high P concentration in the root zone of French marigold (Tagates patula L.) and peppermint (Mentha $\times$ piperita L.) on the development of mycorrhiza has been reported (Schmidt et al. 2010, Cordeiro Silva et al. 2014). Similar results were also obtained by lkiz et al. (2009) in the cultivation of pepper, Cwala et al. (2010) with tomato plants and Cordeiro Silva et al. (2014) with peppermint. Amijee et al. (1989) observed a significant decrease in the number of colonised roots of leeks under conditions of increased $P$ concentration in the soil. The authors suggest that this decrease was caused by a delay in the establishment of contact between fungi and plants, as well as limited hyphae spread within the root system. The development of mycorrhiza is connected with sequestration of signal particles, which are essential to the contact between the fungi and plant (Smith and Read 2008). Akiyama et al. (2005) isolated 5-deoxy-strigol from root exudates of Lotus japonicus, a chemical belonging to the strigolactones, which stimulates branching of germinated hyphae. The sequestration of strigolactones by plant roots is affected by the concentration of $P$ (Yoneyama et al. 2007, 2012). The experiment involving cultivation of red clover demonstrated that sequestration of orobranchol, a sesquiterpene compound, by plant roots was regulated by the concentration of $P$ in the root zone and increased under conditions of decreasing concentration of this macroelement in the root zone (Yoneyama et al. 2007). The level of Se did not affect mycorrhizal parameters.

The lettuce yield, expressed as weight of a single head, was $119 \mathrm{~g}$ and was only affected by Se content of the substrate (Table 2). Doses of Se used in experiment caused a gradual decrease in yield. These differences between plants grown without Se and the highest concentration of this element ( $12 \mathrm{mg} \mathrm{dm}^{-3}$ ) amounted to $35 \%$. There was no harmful effect of Se on the plants, that is, no signs of leaf damage or discoloration.

It is interesting to note the lack of differences in yields with different $\mathrm{P}$ concentrations. Plants grown at a lower $\mathrm{P}$ level in the substrate $\left(70 \mathrm{mg} \mathrm{dm}^{-3}\right)$ were characterised by similar yield as plants grown at optimal concentration of this nutrient $\left(140 \mathrm{mg} \mathrm{dm}^{-3}\right)$. 
Table 2. Effect of mycorrhiza on yield (g) of lettuce grown on medium with different levels of phosphorus and selenium $\left(\mathrm{mg} \mathrm{dm}^{-3}\right)$

\begin{tabular}{lll}
\hline Treatments & & Yield \\
\hline Phosphorus & 70 & 122 \\
& 140 & 117 \\
\cline { 2 - 3 } Mycorrhiza & - AMF & 120 \\
& + AMF & 118 \\
\cline { 2 - 3 } Selenium & 0 & $140 \mathrm{c}$ \\
& 6 & $124 \mathrm{~b}$ \\
& 12 & $93 \mathrm{a}$ \\
\hline \multirow{2}{*}{$p<0.05$} & Phosphorus (A) & n.s. \\
& AMF (B) & n.s. \\
& Selenium (C) & $*$ \\
\hline
\end{tabular}

* = means are significantly different at $p<0.05 ;$ n.s. = differences are not significant; $a, b=$ means followed by different letters differ at $p<0.05$; -AMF/+AMF - non-inoculated plants by arbuscular mycorrhizal fungi (AMF)/inoculated plants by $A M F$; interaction $A \times$ $B, A \times C, B \times C, A \times B \times C-$ not significant

The analysis of mineral composition of plants showed a significantly lower concentration of $\mathrm{P}$ in plants grown at $70 \mathrm{mg} \mathrm{P} \mathrm{dm}^{-3}(0.31 \% \mathrm{~d}$.m.) compared to plants grown at double that concentration, i.e. the optimal concentration of $\mathrm{P}$ in substrate $(0.40 \% \mathrm{~d} . \mathrm{m}$.; Table 3$)$. The differences in content of $\mathrm{P}$ in plants among objects amounted around $25 \%$. Despite these differences, the concentration of $P$ in plants grown at 70 , and $140 \mathrm{mg} \mathrm{P} \mathrm{dm}^{-3}$ was at the optimal level (Hartz et al. 2007), which might result in no effect of $P$ dose on yield. No significant effect of AMF on $P$ concentration in plants was demonstrated which may result from the low relative abundance of arbuscules (Table 1). Arbuscules are bushy-branched ends of hyphae, located in cortical cell of roots, which are involved in nutrient exchange between fungi and plant (Parniske 2008). Low level of arbuscule development, limits the possibility of nutrient exchange between symbiotic organisms, what results in no effect on improvement of plant nutritional status. Similarly, no effect of mycorrhiza on plant nutritional status in $\mathrm{P}$ was proved in the experiment with cultivation of lettuce and tomato plants in mineral and organic growing media (Kowalska et al. 2015a, 2015b). According to Hawkins and George (1997), lack of an increase in P uptake by inoculated plants in soilless cultivation results from presence of this nutrient in easy available forms, what limits the mechanism of improving plant nutritional status by AMF. Many authors have shown the beneficial effect of mycorrhiza on plant nutritional status, especially in terms of P content, in soil cultivation. This is caused by increase in the absorptive surface of root system, penetration of a larger volume of soil and smaller diameter of fungal hyphae than root hair, which enables hyphae to penetrate soil pores with a diameter that makes them unavailable to roots (Smith and Read 2008, Smith et al. 2011). Moreover, AMF produce the enzymes which can soluble such nutrient forms which are not available for plants, e.g. P, thus allowing them to be uptaken by plants (Smith and Read 2008).

Table 3. Effect of mycorrhiza on dry matter (\%) and macronutrient (\% d.m.) contents in lettuce grown on medium with different levels of phosphorus and selenium $\left(\mathrm{mg} \mathrm{dm}^{-3}\right)$

\begin{tabular}{llcccccc}
\hline Treatments & & Dry matter & $\mathrm{N}$ & $\mathrm{P}$ & $\mathrm{K}$ & $\mathrm{Ca}$ & $\mathrm{Mg}$ \\
\hline Phosphorus & 70 & 7.69 & 2.27 & 0.30 & 2.37 & 1.28 & 0.27 \\
& 140 & 7.61 & 2.34 & 0.35 & 2.15 & 1.32 & 0.27 \\
\cline { 2 - 7 } Mycorrhiza & $-\mathrm{AMF}$ & 7.71 & 2.30 & 0.24 & 2.15 & 1.28 & 0.27 \\
& $+\mathrm{AMF}$ & 7.58 & 2.30 & 0.32 & 2.36 & 1.33 & 0.27 \\
\cline { 2 - 7 } Selenium & 0 & 7.49 & 2.26 & 0.34 & $2.53 \mathrm{a}$ & 1.34 & $0.32 \mathrm{c}$ \\
& 6 & 7.42 & 2.30 & 0.33 & $2.31 \mathrm{~b}$ & 1.32 & $0.26 \mathrm{~b}$ \\
& 12 & 8.03 & 2.35 & 0.31 & $1.93 \mathrm{c}$ & 1.25 & $0.23 \mathrm{a}$ \\
\hline$p<0.05$ & Phosphorus (A) & n.s. & n.s. & $*$ & $*$ & n.s. & n.s. \\
& AMF (B) & n.s. & n.s. & n.s. & $*$ & n.s. & n.s. \\
& Selenium (C) & $*$ & n.s. & n.s. & $*$ & n.s. & $*$ \\
\hline
\end{tabular}

$*=$ means are significantly different at $p<0.05 ;$ n.s. = differences are not significant $; \mathrm{a}, \mathrm{b}=$ means followed by different letters differ at $p<0.05$; -AMF/+AMF - non-inoculated plants by arbuscular mycorrhizal fungi $(\mathrm{AMF}) /$ inoculated plants by $A M F$; interaction $A \times B, A \times C, B \times C, A \times B \times C$ - not significant 
In this study, with the exception of $\mathrm{K}$, there was no effect of root inoculation with AMF on the uptake of macroand micro-nutrients by plants (Table 3 and 4). Higher content of $K$ was estimated in inoculated plants compared to those grown without AMF $(2.36 \%$ and $2.15 \% \mathrm{~K}$ in d.m., respectively). The increased concentration of $\mathrm{K}$ in inoculated plants was also reported by Baslam et al. (2013) in lettuce cultivated in a greenhouse. The effect of mycorrhiza on K uptake is not fully understood. Several genes were identified in Rhizophagus irregularis as K transporters, among which some were involved in uptake of $\mathrm{K}^{+}$cations from the soil and some were transporters of $\mathrm{K}^{+}$ from arbuscules to plant cells (Garcia and Zimmermann 2014). As arbuscules are involved in $K$ transport, increased uptake of this nutrient reported in this study at the low level of arbuscule development requires further study.

\begin{tabular}{|c|c|c|c|c|c|c|c|c|}
\hline Treatments & & $\mathrm{Fe}$ & B & $\mathrm{Cu}$ & $\mathrm{Mn}$ & Mo & $\mathrm{Zn}$ & Se \\
\hline \multirow[t]{2}{*}{ Phosphorus } & 70 & 107.90 & 26.55 & 3.06 & 207.66 & 0.85 & 83.34 & 24.44 \\
\hline & 140 & 105.10 & 25.88 & 3.09 & 194.00 & 0.75 & 62.60 & 28.77 \\
\hline \multirow[t]{2}{*}{ Mycorrhiza } & $-\mathrm{AMF}$ & 107.34 & 26.12 & 3.21 & 196.97 & 0.85 & 75.37 & 27.06 \\
\hline & $+\mathrm{AMF}$ & 105.63 & 26.31 & 2.94 & 204.69 & 0.76 & 70.78 & 26.15 \\
\hline \multirow[t]{3}{*}{ Selenium } & 0 & $125.54 c$ & 26.51 & 3.98 & 288.01 & 0.79 & 79.72 & $0.45 a$ \\
\hline & 6 & $104.78 b$ & 26.71 & 2.84 & 190.67 & 0.73 & 68.11 & $28.31 b$ \\
\hline & 12 & $89.19 a$ & 25.42 & 2.41 & 123.82 & 0.88 & 71.39 & $51.06 \mathrm{c}$ \\
\hline \multirow[t]{3}{*}{$p<0.05$} & Phosphorus (A) & n.s. & n.s. & n.s. & n.s. & n.s. & $*$ & $*$ \\
\hline & AMF (B) & n.s. & n.s. & n.s. & n.s. & n.s. & n.s. & n.s. \\
\hline & Selenium (C) & * & n.s. & * & * & n.s. & n.s. & * \\
\hline
\end{tabular}

Content of Se in the substrate affected accumulation of some nutrients in plants. Regardless of the other experimental factors, increasing level of Se in the substrate caused the decrease of $\mathrm{K}, \mathrm{Mg}, \mathrm{Fe}, \mathrm{Cu}$ and $\mathrm{Mn}$ in plants (Table 3 and 4). As reported in the introduction, Se is not an essential element for plants. However, there are more results showing that Se at low concentrations is beneficial element for plants, acting as an antioxidant and growth promoter (Garcia-Bañuelos et al. 2011). This experiment did not demonstrate the beneficial effect of Se on plant yield or the content of macro- and micro-nutrients (Tables 2-4). Both Se doses (6 and $12 \mathrm{mg} \mathrm{dm}^{-3}$ ) caused a decrease in the content of $\mathrm{K}, \mathrm{Mg}, \mathrm{Fe}, \mathrm{Cu}$ and $\mathrm{Mn}$ compared to control plants and the decrease in these nutrients was progressively related to the Se dose. In the studies carried out by Hawrylak-Nowak et al. (2015), the effect of Se on mineral composition of cucumber depended from a dose and form of Se in the nutrient solution. Generally, the highest doses of Se (30-60 $\mu \mathrm{M}$ in the selenite form) caused a decreased content of all nutrients. However, for particular nutrients, the extent of the decrease differed. Plant reaction to the presence of Se in the nutrient solution was also expressed in differences in cucumber biomass. Concentrations of $20 \mu \mathrm{M}$ Se and above (in the form of $\mathrm{Na}_{2} \mathrm{SeO}_{3}$ ) significantly decreased the plant biomass. Plant response to Se concentration depends on the species. Lettuce seems to be more sensitive to selenium concentration than cucumber. Rios et al. (2008) showed a progressive decrease in biomass at concentrations higher than $5 \mu \mathrm{M}$ Se in the nutrient solution, introduced in the form of $\mathrm{Na}_{2} \mathrm{SeO}_{3}$. However, Hawrylak-Nowak (2013) demonstrated the same effect at $15 \mu \mathrm{M} \mathrm{Se}$. However, at low concentrations Se exerted beneficial effects on plant growth. A significant increase in shoot fresh weight in the plants supplemented with 2-10 $\mathrm{MM}$ of selenite was reported (Hawrylak-Nowak 2013). Toxic effects of Se on plants observed in the studies may mainly result from the replacement of S-amino acids by Se-amino acids and their subsequent incorporation into the proteins (Hajiboland and Amjad 2007).

Phosphate transporters are involved in transport of Se absorbed by plants as $\mathrm{SeO}_{3}^{-2}$ (White and Broadley 2009). Also, this element may enter cells by passive mechanisms (Terry et al. 2000) or, as reported in the latest studies, by the aquaporin channel which takes place at low pH in the root zone (Broadley et al. 2012). Therefore, decrease in $\mathrm{P}$ content of lettuce in the presence of Se might result from competition for the transporters. Similarly, in the experiment carried out by Feng et al. (2009), the presence of Se(IV) in nutrient solution decreased the concentration of P in Chinese brake fern. Matraszek and Hawrylak-Nowak (2009), as well as Ramos et al. (2011), also demonstrated the same effect in lettuce. 
The effect of Se on uptake of macro- and micro-nutrients was tested in many studies and depends mainly on dose and form of Se in the root zone. Hawrylak-Nowak et al. (2015) observed a decrease in the content of $\mathrm{K}$ and $\mathrm{Mg}$ in cucumber leaves when Se was applied as selenite in doses of 30 and $40 \mu \mathrm{M}$, respectively. On the other hand, it was demonstrated that a lower level of Se may have a synergistic effect on other compounds which are considered as essential.

In this study, Se content of lettuce was affected by dose of $\mathrm{P}$ and Se in the substrate. There was no mycorrhiza effect on accumulation of this nutrient (Table 4). Inoculated and non-inoculated plants accumulated a similar content of Se (26.15 and $27.06 \mathrm{mg} \mathrm{kg}^{-1} \mathrm{~d} . \mathrm{m}$. , respectively). This is not surprising, especially considering the lack of effect of AMF on nutrient content of plants, with the exception of K. As reported above, in soilless cultures, the effect of mycorrhiza on nutrient uptake is unequivocal. Optimal content of $P$ in substrate contributed to accumulation of more Se content in plants $\left(28.77 \mathrm{mg} \mathrm{kg}{ }^{-1} \mathrm{~d} . \mathrm{m}\right.$. at $140 \mathrm{mg} \mathrm{P} \mathrm{dm}^{-3}$ of substrate and $24.44 \mathrm{mg} \mathrm{kg}^{-1} \mathrm{~d} . \mathrm{m}$. at $70 \mathrm{mg} \mathrm{P} \mathrm{dm}^{-3}$ ). The most visible differences in plant Se content occurred as an effect of Se presence in the substrate. Both Se doses ( 6 and $12 \mathrm{mg} \mathrm{dm}^{-3}$ ) caused a significant increase in the concentration of this element in substrate. This increase was linear, i.e. increase in Se dose caused a proportional increase in the concentration of this element in plants.

The total content of sugars in plants was in the range 3377 to $3633 \mathrm{mg}$ per $100 \mathrm{~g}$ fresh matter and was not affected by experimental factors (Table 5). There was a slightly different effect of experimental factors on the content of particular sugars, i.e. sucrose, glucose, fructose. Sucrose content was affected by $\mathrm{P}$ level in the substrate and plants grown at decreased level of $P$ in the substrate were characterised by higher content of sucrose. Se levels had an effect on content of fructose in leaves. Increased dose of Se (6 and $\left.12 \mathrm{mg} \mathrm{dm}^{-3}\right)$ contributed to the increased concentration of fructose in lettuce leaves. Experimental factors did not affect glucose content in lettuce.

Table 5. Effect of mycorrhiza on content of sugars ( $\mathrm{mg} 100 \mathrm{~g}^{-1} \mathrm{f}$.m.) in lettuce grown on medium with different levels of phosphorus and selenium $\left(\mathrm{mg} \mathrm{dm}^{-3}\right)$

\begin{tabular}{|c|c|c|c|c|c|}
\hline Treatments & & Sucrose & Glucose & Fructose & Total sugars \\
\hline \multirow[t]{2}{*}{ Phosphorus } & 70 & 427 & 1330 & 1771 & 3529 \\
\hline & 140 & 377 & 1290 & 1845 & 3513 \\
\hline \multirow[t]{2}{*}{ Mycorrhiza } & $-\mathrm{AMF}$ & 410 & 1296 & 1815 & 3521 \\
\hline & $+\mathrm{AMF}$ & 394 & 1325 & 1801 & 3521 \\
\hline \multirow[t]{3}{*}{ Selenium } & 0 & 393 & 1307 & $1750 a$ & 3450 \\
\hline & 6 & 400 & 1299 & $1809 a b$ & 3508 \\
\hline & 12 & 413 & 1324 & $1866 b$ & 3604 \\
\hline \multirow[t]{3}{*}{$p<0.05$} & Phosphorus (A) & $*$ & n.s. & n.s. & n.s. \\
\hline & AMF (B) & n.s. & n.s. & n.s. & n.s. \\
\hline & Selenium (C) & n.s. & n.s. & $*$ & n.s. \\
\hline
\end{tabular}

* = means are significantly different at $p<0.05 ;$ n.s. = differences are not significant ; $\mathrm{a}, \mathrm{b}=$ means followed by different letters differ at $p<0.05$; $-\mathrm{AMF} /+\mathrm{AMF}$ - non-inoculated plants by arbuscular mycorrhizal fungi (AMF)/inoculated plants by AMF; interaction $A \times B, A \times C, B \times C, A \times B \times C$ - not significant

Arbuscular mycorrhiza is a type of symbiosis where both partners have benefits. AMF support plants in the uptake of nutrients and water, which results in decreased energy cost to plants of nutrient uptake. As a result of symbiosis, fungi receive carbohydrates from plants (Smith and Read 2008). According to Parniske (2008), up to 20\% of carbon present in plants can be transported to AMF. In this study, there was no effect of mycorrhiza on total sugars and each type of sugar. Inoculated and non-inoculated plants had the same content of carbohydrates. It can be assumed that if AMF did not affect the content of nutrients in plants or carbohydrate content, and there was no exchange of benefits resulting from symbiosis. Moreover low relative abundance of arbuscules, i.e. places of exchange of nutrients between fungi and plant, confirms an absence of the benefits of symbiosis.

\section{Conclusions}

The obtained results confirmed that the development of mycorrhizal structures depends on P level in the root zone of plants and that it is limited at the optimal concentration of P. On the other hand, the presence of Se had no effect on the level of mycorrhiza. There was no effect of mycorrhiza on plant Se uptake; both mycorrhized and non-mycorrhized plants accumulated a similar amount of Se. Similarly, there was an absence of any effect of mycorrhiza on the content of almost all estimated macro- and micronutrients. An increased Se concentration in the medium caused a decrease in $\mathrm{K}, \mathrm{Mg}$, Fe, $\mathrm{Cu}$ and $\mathrm{Mn}$ concentrations in lettuce. 


\section{Acknowledgements}

This research was financed by the Ministry of Science and Higher Education of the Republic of Poland.

\section{References}

Akiyama, K., Matsuzaki, K. \& Hayashi, H. 2005. Plant sesquiterpens induce a hyphal branching in arbuscular mycorrhizal fungi. Nature 435: 824-827. https://doi.org/10.1038/nature03608

Amijee, F., Tinker, P.B. \& Stribley, D.P. 1989. The development of endomycorrhizal root systems. VII: a detailed study of effects of soil phosphorus on root colonization. New Phytologist 111: 435-446. https://doi.org/10.1111/j.1469-8137.1989.tb00706.x

Baslam, M., Morales, F., Garmendia, I. \& Goicoechea, N. 2013. Nutritional quality of outer and inner leaves of green and red pigmented lettuces (Lactuca sativa L.) consumed as salads. Scientia Horticulturae 151: 103-111. https://doi.org/10.1016/j.scienta.2012.12.023

Broadley, M.R., Brown, P., Cakmak, I., Feng, M.J., Rengel, Z. \& Zhao, F. 2012. Beneficial elements. In: Marschner, P. (ed.). Mineral nutrition of higher plants, 3rd edn. London: Academic Press. p. 249-269. https://doi.org/10.1016/B978-0-12-384905-2.00008-X

Cordeiro Silva, V., Casaes Alves, P.A., de Oliveira, R.A., de Jesus, R.M., do Bomfim Costa, L.C. \& Gross, E. 2014. Influence of arbuscular mycorrhizal fungi on growth, mineral composition and production of essential oil in Mentha $\times$ piperita L. var. citrata (Ehrh.) Briq. under two phosphorus levels. Journal of Medicinal Plants Research 8: 1321-1332. https://doi.org/10.5897/JMPR2014.5689

Cwala, Y., Laubscher, C.P., Ndakidemi, P.A. \& Meyer, A.H. 2010. Mycorrhizal root colonization and the subsequent host plant response of soil less grown tomato plants in the presence and absence of the mycorrhizal stimulant, Mycotech. African Journal Microbiology Research 4: 414-419.

Feng, R., Wei, C., Tu, S. \& Sun, X. 2009. Interactive effects of selenium and arsenic on their uptake by Pteris vittata L. under hydroponic conditions. Environmental and Experimental Botany 65: 363-368. https://doi.org/10.1016/j.envexpbot.2008.11.013

Gryndler, M., Larsen, J., Hršelová, H., Řezáčová, V., Gryndlerová, H. \& Kubát, J. 2006. Organic and mineral fertilization, respectively, increase and decrease the development of external mycelium of arbuscular mycorrhizal fungi in long-term field experiment. Mycorrhiza 16: 159-166. https://doi.org/10.1007/s00572-005-0027-4

Garcia, K. \& Zimmermann, S.D. 2014. The role of mycorrhizal associations in plant potassium nutrition. Frontiers in Plant Science 5: 337. https://doi.org/10.3389/fpls.2014.00337

Garcia-Bañuelos, M.L., Hermosillo-Cereceres, M.A. \& Sánchez, E. 2011. The importance of selenium biofortification in food crops. Current Nutrition Food Science 7: 181-190. https://doi.org/10.2174/157340111797264796

Hajiboland, R. \& Amjad, L. 2007. Does antioxidant capacity of leaves play a role in growth response to selenium at different sulphur nutritional status? Plant, Soil and Environment 53: 207-215. https://doi.org/10.17221/2202-PSE

Hartz, T.K., Johnstone, P.R., Williams, E. \& Smith, R.F. 2007. Establishing Lettuce Leaf Nutrient Optimum Ranges Through DRIS Analysis. HortScience 42: 143-146. https://doi.org/10.21273/HORTSCI.42.1.143

Hawkins, H.J. \& George, E. 1997. Hydroponic culture of the mycorrhizal fungus Glomus mosseae with Linum usitatissimum L., Sorghum bicolor L. and Triticum aestivum L. Plant and Soil 196: 143-149.

Hawrylak, B. \& Szymańska, M. 2007. Selected aspects of antioxidation and pro-oxidative Se activity in corn roots (Zea mays L.) 2007. Roczniki AR w Poznaniu - CCCLXXXIII: 487-491. (in Polish).

Hawrylak-Nowak, B. 2013. Comparative effects of selenite and selenate on growth and selenium accumulation in lettuce plants under hydroponic conditions. Plant Growth Regulation 70: 149-157. https://doi.org/10.1007/s10725-013-9788-5

Hawrylak-Nowak, B., Matraszek, R. \& Pogorzelec, M. 2015. The dual effects of two inorganic selenium forms on the growth, selected physiological parameters and macronutrients accumulation in cucumber plants. Acta Physiologiae Plantarum 37:41. https://doi.org/10.1007/s11738-015-1788-9

Ikiz, O., Abak, K., Daşgan, H.Y. \& Ortaş, I. 2009. Effects of mycorrhizal inoculation in soilless culture on pepper plant growth. Acta Horticulturae 807: 533-540. https://doi.org/10.17660/ActaHortic.2009.807.78

Kowalska, I., Konieczny, A. \& Gąstoł, M. 2015a. Effect of mycorrhiza and phosphorus content in nutrient solution on the yield and nutritional status of lettuce grown on various substrates. Journal of Elementology 20: 631-642. https://doi.org/10.5601/ jelem.2014.19.4.789

Kowalska, I., Konieczny, A., Gąstoł, M., Sady, W. \& Hanus-Fajerska, E. 2015b. Effect of mycorrhiza and phosphorus content in nutrient solution on the yield and nutritional status of tomato plants grown on rockwool or coconut coir. Agricultural and Food Science 24: 39-51. https://doi.org/10.23986/afsci.47204

Lyons, G., Genc Y., Soole, K., Stangoulis, J.C., Liu, F. \& Graham, R.D. 2009. Selenium increases seed production in Brassica. Plant and Soil 318: 73-80. https://doi.org/10.1007/s11104-008-9818-7

Matraszek, R. \& Hawrylak-Nowak, B. 2009. Macronutrients accumulation in useable parts of lettuce as affected by nickel and selenium concentrations in nutrient solution. Fresenius Environmental Bulletin 18: 1059-1065.

Parniske, M. 2008. Arbuscular mycorrhiza: the mother of plant root endosymbioses Nature Reviews Microbiology 6: 763-775. https://doi.org/10.1038/nrmicro1987

Pasławski, P. \& Migaszewski, Z.M. 2006. The quality of element determinations in plant materials by instrumental methods. Polish Journal of Environmental Studies 15: 154-164.

Persson, J.A. \& Wennerholm, M. 1999. Kjeldahl's handbook of mineralization. Warsaw: Labconsult. (in Polish). 
Phillips, J.M. \& Hayman, D.S. 1970. Improved procedures for clearing roots and staining parasitic and vesicular - arbuscular mycorrhizal fungi for rapid assessment of infection. Transactions of the British Mycological Society 55: 158-161. https://doi.org/10.1016/ S0007-1536(70)80110-3

PN-EN 15111 (2008). Foodstuffs - determination of trace elements - determination of iodine by ICP-MS (inductively coupled plasma mass spectrometry). Polish Committee of Standardisation, Warsaw. (In Polish).

Pilon-Smits, E.A.H., Quinn, C.F., Tapken, W., Malagoli, M. \& Schiavon, M. 2009. Physiological functions of beneficial elements. Current Opinion Plant Biology 12: 267-274. https://doi.org/10.1016/j.pbi.2009.04.009

Ramos, S.J., Faquin, V., de Almeida, H.J., Ávila, F.W., Guimarães Guilherme, L.R., Alves Bastos, C.E. \& Ávila, P.A. 2011. Selenate and selenite on yield, mineral nutrition and biofortification with selenium in lettuce cultivars. Revista Brasileira de Ciência do Solo 35 : 1347-1355. https://doi.org/10.1590/S0100-06832011000400029

Rios, J.J., Blasco, B., Cervilla, L.M., Rubio-Wilhelmi, M.M., Ruiz, J.M. \& Romero, L. 2008. Regulation of sulphur assimilation in lettuce plants in the presence of selenium. Plant Growth Regulation 56: 43-51. https://doi.org/10.1007/s10725-008-9282-7

Schmidt, B., Domonkos, M., Sumalan, R. \& Biro, B. 2010. Suppression of arbuscular mycorrhiza's development by high concentrations of phosphorus at Tagetes patula L. Research Journal Agricultural Science 42: 156-162.

Smith, S.E., Jakobsen, I., Grønlund, M. \& Smith, F.A. 2011. Roles of arbuscular mycorrhizas in plant phosphorus nutrition: Interactions between pathways of phosphorus uptake in arbuscular mycorrhizal roots have important implications for understanding and manipulating plant phosphorus acquisition. Plant Physiology 156: 1050-1057. https://doi.org/10.1104/pp.111.174581

Smith, S.E. \& Read, D.J. 2008. Mycorrhizal symbiosis. 3rd ed. Great Britain: Elsevier LTD. 800 p.

Terry, N., Zayed, M., De Souza, M.P. \& Tarun, A.S. 2000. Selenium in higher plants. Annual Review of Plant Physiology and Plant Molecular Biology 51: 401-432. https://doi.org/10.1146/annurev.arplant.51.1.401

Trouvelot, A., Kough, J.L. \& Gianinazzi-Pearson, V. 1986. Mesure du taux de mycorrhization VA d'un systeme radiculaire. Recherche de methods d'estimation ayant une signification fonctionnelle. In: Gianinazzi-Pearson, V. \& Gianinazzi, S. (eds.). Physiological and genetical aspects of mycorrhizae. Paris: INRA. p. 217-221.

White, P.J. \& Broadley, M.R. 2009. Biofortification of crops with seven mineral elements often lacking in human diets - iron, zinc, copper, calcium, magnesium, selenium and iodine. New Phytologist 182: 49-84. https://doi.org/10.1111/j.1469-8137.2008.02738.x

Yoneyama, K., Xie, X., Kim, H.I., Kisugi, T., Nomura, T., Sekimoto, H., Yokota, T. \& Yoneyama, K. 2012. How do nitrogen and phosphorus deficiencies affect strigolactone production and exudation? Planta 235: 1197-1207. https://doi.org/10.1007/s00425-011-1568-8

Yoneyama, K., Yoneyama, K., Takeuchi, Y. \& Sekimoto, H. 2007. Phosphorus deficiency in red clover promotes exudation of orobranchol, the signal for mycorrhizal symbionts and germination stimulant for root parasites. Planta 225: 1031-1038. https://doi. org/10.1007/s00425-006-0410-1 